\title{
Structural and Thermophysical Properties of Magnetic Beads Containing Metallic Nanocrystallites
}

\author{
M. IZYdORZAK ${ }^{a}$, M. LEONOWICZ ${ }^{a}$ AND A. SKUMIEL ${ }^{b}$ \\ ${ }^{a}$ Faculty of Materials Science and Engineering, Warsaw University of Technology \\ Wołoska 141, 02-507 Warsaw, Poland \\ ${ }^{b}$ Institute of Acoustics, Faculty of Physics, Adam Mickiewicz University, Umultowska 85, 61-614 Poznań, Poland
}

\begin{abstract}
Cobalt, iron, nickel and iron carbide nanocrystallites, stabilized within carbon beads, were prepared by the three-step procedure including formation of metal acrylamide complex, followed by frontal polymerization and pyrolysis of the polymer at various temperatures. The beads containing the nanocrystallites exhibit domination of the ferromagnetic ordering. The analysis of calorimetric results allowed estimation of the efficiency of the hyperthermal effect, under the influence of an alternating magnetic field. The XTT tests show that the extracts prepared on the basis of the $\mathrm{Fe}_{3} \mathrm{C}$ containing beads are nontoxic, whereas these made of the composites containing $\mathrm{Co}$ and $\mathrm{Ni}$ exhibit negligible cytotoxicity for the test article/vehicle ratios 6.25 and $3.125 \mathrm{mg} / \mathrm{ml}$.
\end{abstract}

PACS: 75.50.Bb, 75.75.-c, 81.07.-b

\section{Introduction}

Magnetic nanostructures belong to the group of materials which recently are extensively studied in respect of their applications in biology and medicine.

Among the most important applications one can mention detection and analysis of bioparticles, targeted drug delivery, contrast material for magnetic resonance imaging and hyperthermia. The scope of the research comprises fabrication methods of nanoparticles, their stabilization, methods of their functionalization, biocompatibility tests and problems of vesicular transport. The important issue is a proper choice of the size of the magnetic carriers, which determines their access to blood vessels, which have sizes in a broad range from $30 \mu \mathrm{m}$ up to $2.5 \mathrm{~mm}$ [1]. From this point of view the nanoparticles should be as small as possible, however, in such a case the forces acting on the particle in an external magnetic field, which are proportional to its volume, may be too small. In biomedical applications the nanoparticles can exist as individual crystallites [2] or be incorporated in biocompatible beads [3].

In this study the method based on pyrolysis of polymers containing atoms of basic ferromagnetic elements $\mathrm{Fe}$, Co and Ni was applied for formation of beads containing magnetic nanocrystallites. Structure, microstructure and magnetic properties of the materials were characterized. The beads may potentially be used as biological sensors, for targeted drug delivery and hyperthermia.

\section{Experimental}

The acrylamide metal complexes containing atoms of $\mathrm{Co}, \mathrm{Ni}$ and $\mathrm{Fe}$ were obtained by substitution reac- tion of inorganic hydrates by acrylamide. Frontal polymerization was carried out at atmospheric pressure in self-generated atmosphere. The nanocomposites were formed by further pyrolysis. More detailed description of the processing route, as well as the products, can be found in [4].

The structure of the material, after all stages of preparation, was studied by X-ray diffraction (XRD) (Rigaku Miniflex, $\mathrm{Cu} K_{\alpha}$ ) and the Raman spectroscopy (Nicolet Almega XR). Microstructure was analyzed using scanning electron microscope (SEM) (Hitachi S-3500) and transmission electron microscope (TEM) (JEOL JEM $1200 \mathrm{EX}$ ). The hysteresis loops were recorded at room temperature, in an external magnetic field of $\pm 1600 \mathrm{kA} / \mathrm{m}$.

The magnetic field frequencies $f=500 \mathrm{kHz}$ and $450 \mathrm{kHz}$ were selected for the study of hyperthermal effect. The temperature of a sample was monitored using a thermocouple (LT Lutron TM-917) with absolute accuracy $\pm 0.01{ }^{\circ} \mathrm{C}$.

For evaluating the potential cytotoxicity of the Co, $\mathrm{Fe}_{3} \mathrm{C}$ and $\mathrm{Ni}$ containing nanocomposites, the Cell Proliferation Kit (XTT) was used.

\section{Results and discussion}

The as-received powder beads have irregular shape and sizes ranging from few to several hundreds of micrometers. After milling for $60 \mathrm{~min}$ in a ball mill their size can be reduced to a mean size of $5 \mu \mathrm{m}$ with a narrow size distribution (Fig. 1). Magnetic measurements revealed that the properties do not change in the course of milling. The Raman spectroscopy showed that the matrix of the beads is built of both, amorphous carbon and graphite. 

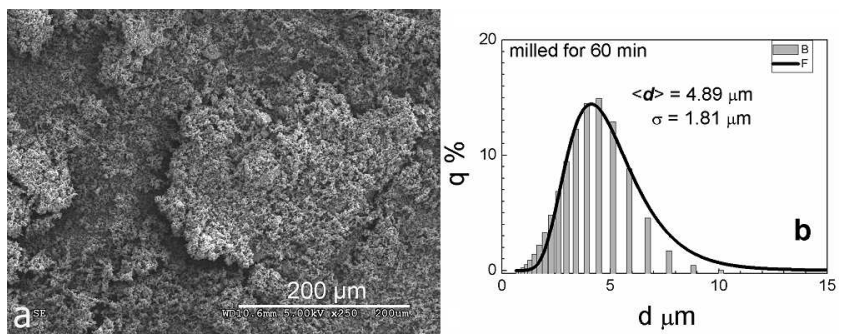

Fig. 1. SEM micrograph of the bead's morphology (a) and their size distribution after milling for $60 \mathrm{~min}$ (b).

The bead's volume is filled with magnetic nanocrystallites (Fig. 2). The Co containing polymer was pyrolysed at temperature 773,873 and $1073 \mathrm{~K}$, respectively. The crystallites produced at these temperatures had mean sizes 10, 11 and $13 \mathrm{~nm}$, respectively. The X-ray diffraction showed reflections characteristic of $\beta$ cobalt, with fcc structure and lattice parameter $a=0.35 \mathrm{~nm}$.

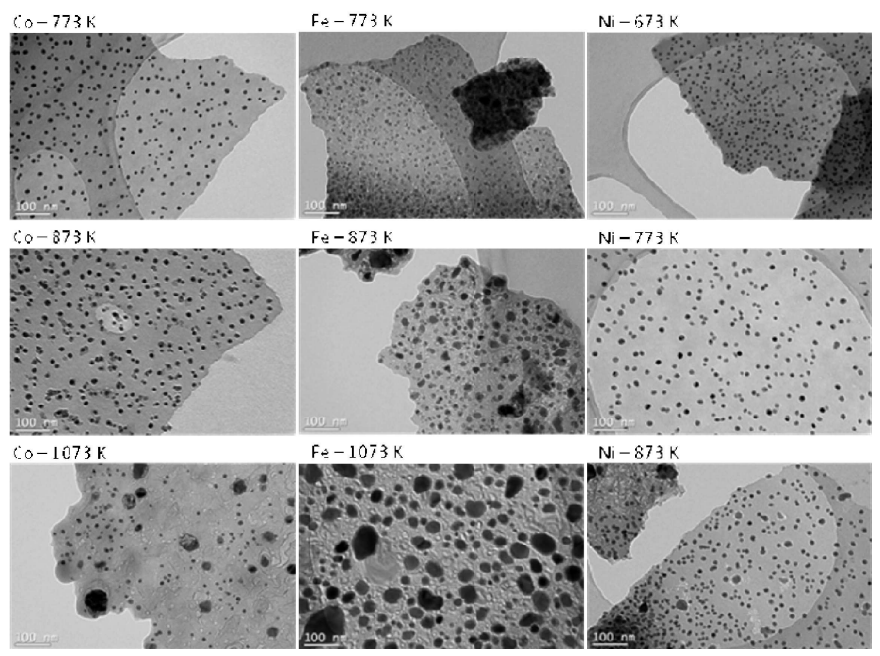

Fig. 2. TEM microstructures of magnetic beads showing distribution of magnetic nanocrystallites within their volume, for materials containing $\mathrm{Co}, \mathrm{Fe}, \mathrm{Fe}_{3} \mathrm{C}$ and $\mathrm{Ni}$, pyrolysed at various temperature.

The lowest pyrolysis temperature which produced nanocrystallites in the Fe containing polymer was $773 \mathrm{~K}$. At this temperature $10 \mathrm{~nm}$ mean size $\alpha$-Fe nanocrystallites were formed. Application of the pyrolysis temperature $873 \mathrm{~K}$ and $1073 \mathrm{~K}$ resulted in formation of iron carbide $\mathrm{Fe}_{3} \mathrm{C}$.

The polymer containing nickel was pyrolysed at 673 , 773 and $873 \mathrm{~K}$, respectively. For all these temperatures the nanocrystallites of metallic fcc nickel were obtained. Depending on the processing temperature the mean crystallite sizes were 7,10 and $15 \mathrm{~nm}$, respectively.

The room temperature magnetic properties of the beads are summarized in Table. The coercive force depends on the material microstructure and composition.
For the elementary metals, Co and $\mathrm{Ni}$ the coercive force is in the range of kiloamperes per meter, which suggests that some carbon must have been dissolved in the metals. For the intermetallic phase $\mathrm{Fe}_{3} \mathrm{C}$ the coercive force is obviously much higher due to the more complex structure. The saturation magnetization depends on both, the material type and fraction of the magnetic component. The latter depends on the pyrolysis temperature. The remanence is controlled jointly by the coercive force and saturation magnetization.

In Fig. 3 experiments of heating abilities of the composite beads at alternated magnetic field are shown. Such procedure can be used in hyperthermia treatment which is based on introduction of magnetic particles to the tumor area and heating the tissue to temperature in the range of $\approx 43-46^{\circ} \mathrm{C}$. This action promotes the efficiency of chemotherapy. In the examples shown in Fig. 4 the time dependent changes of the magnetic samples temperature, for the samples subjected to a various alternate magnetic field strength at a frequency of $f=500$ and $450 \mathrm{kHz}$ (chosen as optimal for each material) are presented. It is apparent from these studies that both materials can easily achieve the required temperature within less than $1 \mathrm{~min}$, at a field of few $\mathrm{kA} / \mathrm{m}$.
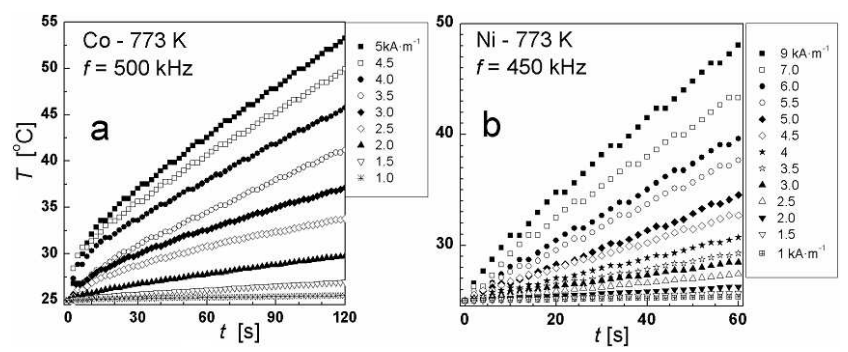

Fig. 3. Temperature-time curves for Co (a) and Ni (b) containing samples pyrolysed at $773 \mathrm{~K}$. Magnetic field frequency $f=500$ and $450 \mathrm{kHz}$ for various magnetic field strength.

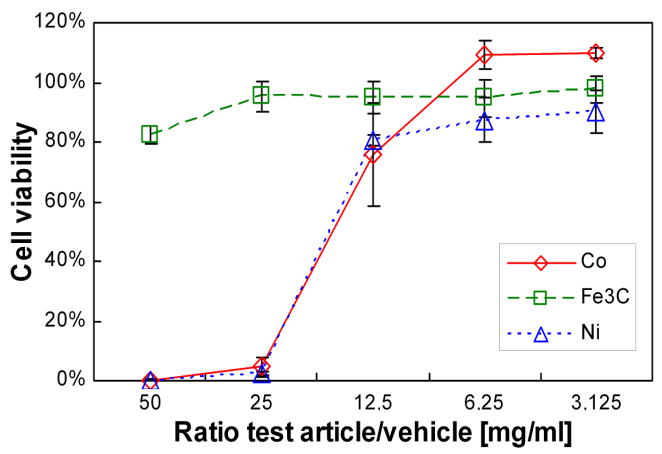

Fig. 4. Cells viability extraction concentrations 50, 25, $12.5,6.25$ and $3.125 \mathrm{mg} / \mathrm{ml}$ for the beads containing Co, $\mathrm{Fe}_{3} \mathrm{C}$ and Ni nanocrystallites. 
TABLE

Parameters of magnetic hysteresis loops for various beads processed at various temperature and respective fraction of the magnetic component.

\begin{tabular}{l|c|c|c|c}
\hline \hline Sample type & $\begin{array}{c}\text { Coercive force } \\
{[\mathrm{kA} / \mathrm{m}]}\end{array}$ & $\begin{array}{c}\text { Remanence } \\
{[\mathrm{A} \mathrm{m} / \mathrm{kg}]}\end{array}$ & $\begin{array}{c}\text { Saturation } \\
\text { magnetization } \\
{\left[\mathrm{A} \mathrm{m}^{2} / \mathrm{kg}\right]}\end{array}$ & $\begin{array}{c}\text { Fraction } \\
\text { of magnetic } \\
\text { component } \\
{[\%]}\end{array}$ \\
\hline $\mathrm{Co}-773 \mathrm{~K}$ & 6.65 & 3.55 & 19.78 & 12 \\
$\mathrm{Co}-873 \mathrm{~K}$ & 2.55 & 2.06 & 31 & 19 \\
$\mathrm{Co}-1073 \mathrm{~K}$ & 30.46 & 12.36 & 55.36 & 34 \\
$\mathrm{Fe}-773 \mathrm{~K}$ & 7.96 & 1.27 & 11.75 & 7 \\
$\mathrm{Fe}-873 \mathrm{~K}$ & 46.43 & 10.15 & 33.31 & 19 \\
$\mathrm{Fe}-1073 \mathrm{~K}$ & 40.24 & 8.24 & 38.72 & 22 \\
$\mathrm{Ni}-673 \mathrm{~K}$ & 2.31 & 0.086 & 3.88 & 7 \\
$\mathrm{Ni}-773 \mathrm{~K}$ & 0.86 & 0.33 & 11.43 & 21 \\
$\mathrm{Ni}-873 \mathrm{~K}$ & 11.09 & 4.44 & 17.49 & 32
\end{tabular}

In Fig. 4 the results of the XTT test for the materials containing $\mathrm{Co}, \mathrm{Fe}_{3} \mathrm{C}$, Ni nanocrystallites are shown. The extraction vehicle consisted of DMEM (Dulbecco's Modified Eagle Medium, 88 \%) supplemented with L-glutamine and antibiotic. Under the condition of the tests, extracts on the basis of the composites containing $\mathrm{Fe}_{3} \mathrm{C}$ showed very low cytotoxicity with a maximum percentage of the cell reduction of $18 \%$ for the highest test article/vehicle ratio, i.e. $50 \mathrm{mg} / \mathrm{ml}$. The XTT test results, for the beads containing $\mathrm{Co}$ and $\mathrm{Ni}$ crystallites, showed that their extracts caused much higher cell mortality. However, the extracts of the lowest test article/ vehicle ratios, i.e. 6.25 and $3.125 \mathrm{mg} / \mathrm{ml}$, were apparently much less toxic.

\section{Conclusions}

Application of frontal polymerization and further pyrolysis enables formation of composite beads consisting of $\mathrm{Co}, \mathrm{Fe}, \mathrm{Fe}_{3} \mathrm{C}$ or Ni spherical nanocrystallites stabilized in carbon matrix. The matrix is built of amorphous carbon and graphite. The magnetic properties of the beads depend on the crystallite type and the volume fraction of the metallic component. The beads can be applied in magnetic hyperthermia. Extracts on the basis of composites containing $\mathrm{Fe}_{3} \mathrm{C}$ showed no cytotoxicity, whereas these containing $\mathrm{Co}$ and $\mathrm{Ni}$ exhibited negligible cytotoxicity for test article/vehicle ratios 6.25 and $3.125 \mathrm{mg} / \mathrm{ml}$.

\section{Acknowledgments}

Financial support from the Ministry of Science and Higher Education (grant No. N N507 276136) is gratefully acknowledged.

\section{References}

[1] T.T. Sandor, D.F. Adams, Am. J. Roentg. 132, 433 (1997).

[2] C. Brigger, C. Dubernet, P. Couvreur, Adv. Drug. Deliv. Rev. 54, 632 (2002).

[3] E. Sowka, M. Leonowicz, A.D. Pomogailo, G.I. Dzhardimalieva, J. Kazmierczak, A. Slawska-Waniewska, M. Kopcewicz, J. Magn. Magn. Mater. 316, 749 (2007).

[4] A.D. Pomogailo, G.I. Dzhardimalieva, Achiev. Problems, Polym. Sci. Ser. A 46, 250 (2004). 